\title{
A 2K-h single-row planetary gearbox optimal design with Genetic Algorithms
}

\author{
Ovidiu BUIGA
}

\author{
Technical University of Cluj-Napoca, Faculty of Machine Building, Bvd. Muncii 103-105, 400641 \\ Cluj-Napoca, Romania \\ Ovidiu.Buiga@omt.utcluj.ro
}

\begin{abstract}
Keywords: Automated design optimization, Genetic Algorithms, 2K-h single-row planetary gearbox
\end{abstract}

\begin{abstract}
In conventional methods, designing a gear drive such as a $2 \mathrm{~K}-\mathrm{h}$ single-row planetary gearbox requires a very large number of calculations based on recommended gear standards, trial and error methods, etc. This time consuming process may often finish up with inadequate design outcomes. Therefore, in this paper a Genetic Algorithm (GA) methaeuristics is considered in order to resolve this complex design problem. The GA was used to find the optimal values of 14 genes (i.e. design variables) that define the planetary gearbox. The optimal design of the power transmission was evaluated considering the mass minimization criterion. The results of the optimised planetary gearbox suggest a reduction of the mass with $15.16 \%$ as compared with the situation when the traditional design was used.
\end{abstract}

\section{Introduction}

In general in order to obtain the required power and kinematic parameters of an actuating element (e.g. car steering wheels, work spindles etc.) which is a part of a mechanical power transmission system, driving gears are used. Gears are widely applied in real-world engineering application from different fields and in various working conditions, and gear design is still an ongoing activity. Designing of gears is a very complex task which arises from strong and often intractable connections between the design variables which can be integer (e.g. number of teeth on gears), discrete (e.g. module, centre distance, etc.), and real (e.g. gear width) that define a gearing. The last decades have seen an increasing awareness amongst the mechanical power transmission design community of the shortfalls of simple trial and error type methods conventionally used to tackle this highly constrained class of design problems. As opposite, the traditional design (i.e. a simple trial and error type methods-used to solve this gear design problem) is utilized less and less.

The potential replacements have begun to emerge in the shape of computer programs. Thus, Madhusudan and Vijayasimha [1] presented a computer program in order to design a required type of gear under a specified set of working conditions. In [2], Aberšek et al. presented an expert system (called STATEX) for dimensioning, optimization and manufacture of gears and gearing. The optimal dimensions of gearing were determined by using GA. Gologlu and Zeyveli in [3] described a stochastic approach GA, applied to a parallel axis two stage helical gear train. The design variables used to describe the objective function were: the normal module, the number of teeth and the face width. The objective function was subjected to a set of 12 constraints. In [4], Buiga and Popa described a GA for designing a single-stage helical gear speed reducer. In [5] is presented a two-phase evolutionary algorithm used for automated optimal design of a two-stage helical gear reducer. In [6], Salgado and Alonso optimised a planetary gear trains (PGTs) used in mechanical spindle speeders by minimising the volume and the kinetic energy. In this paper we deal with a $2 \mathrm{~K}-$ $\mathrm{h}$ single-row planetary gearbox, whose every element (gears, input/output-shafts, radial seal, radial ball bearing, the shape of the housing etc.) is subjected to changes during the optimization process. In Section 2 is presented the statement of optimization problem-containing a complete discussion regarding: the 'chromosome' (i.e. the 14 design variables) of the planetary transmission, the 
objective function (i.e. the mass of the planetary gearbox) and the constraints. Section 3 presents the optimal design problem formulation followed by a discussion and a comparison of the results offered by using the traditional and optimal design methods.

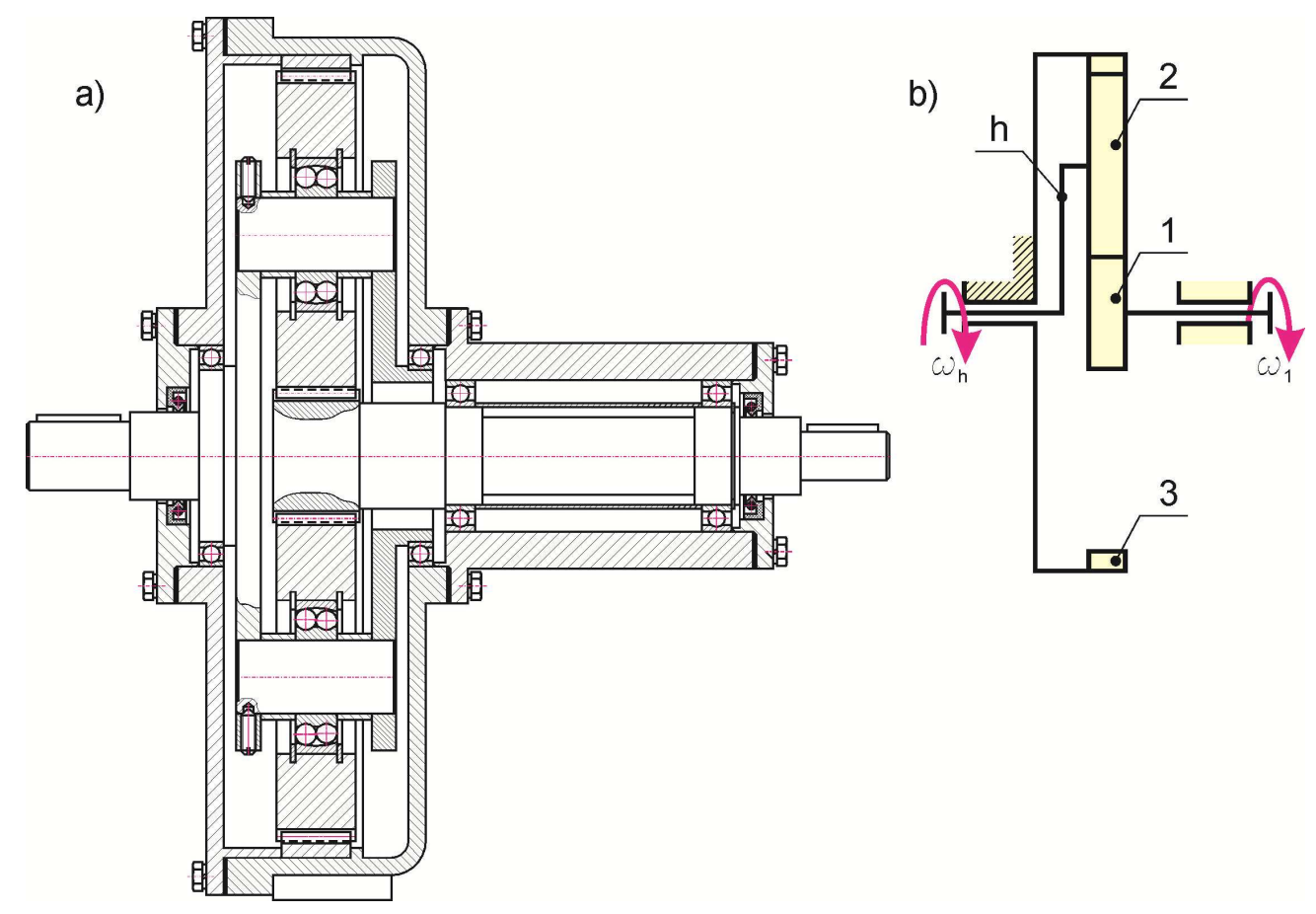

Fig 1 A 2 K-h single-row planetary gearbox

\section{The statement of the optimal design problem}

The 'genotype' of the 2 K-h single-row planetary gearbox. The mechanical power transmission which is considered in this work (Fig. 1 - a $2 \mathrm{~K}-\mathrm{h}$ single-row planetary gearbox i.e., $2 K$ - two central wheels and the carrier $h$ [10]) is defined by a set of 14 design variables. As it can be observed in the following list, from the set of 14 design variables 8 are standardized (i.e. $a_{w}, i_{1}$, $i_{2}, i_{3}, i_{4}, i_{5}, i_{6}$ and $\left.i_{7}\right)$.

- $\boldsymbol{z}_{1}$ is the number of teeth on central wheel (1), integer values $\{21,22,23,24\}$;

- $\boldsymbol{n}_{\boldsymbol{w}}$ represents the number of the planetary pinions, integer values $\{2,3,4,5\}$;

- $\boldsymbol{a}_{\boldsymbol{w}}$ is the center distance of the gearings, standardized, discrete real values within the range: $\{56, \ldots, 315\}$;

- $\psi_{a}$ is the tooth addendum coefficient of central wheel (1), real values in the range [-0.5 $, \ldots, 1]$

- $\boldsymbol{x}_{\mathbf{1}}$ is the coefficient of the ratio between the central pinion (1) width and center distance, Real values within the range $[0.2, \ldots, 0.8]$;

- $\Delta \boldsymbol{u}$ is the relative error of the gear ratio, real values in the range $[-0.04, \ldots,+0.04]$;

- $\quad \boldsymbol{r} \boldsymbol{d}$ represents the round direction, integer values $\{0,1\}$;

- $\boldsymbol{i}_{1}$ is the index of standardized end for the input shaft, integer values in the range $[0, \ldots$, 63];

- $\boldsymbol{i}_{\mathbf{2}}$ is the index of standardized radial shaft seal for the input shaft, integer values in the range: $[0, \ldots, 127]$;

- $\boldsymbol{i}_{3}$ is the index of radial ball bearings for the input shaft, integer values in the range $[0, \ldots$, 127];

- $\quad \boldsymbol{i}_{4}$ is the index of self-aligning ball bearings for mounting the planetary pinions (2), integer values within the range of $[0, \ldots, 31]$; 
- $\boldsymbol{i}_{5}$ is the index of radial ball bearings for the output shaft, integer values in the range [0 $, \ldots, 127]$

- $\boldsymbol{i}_{6}$ is the index of standardized end for the output shaft, integer values in the range $[0, \ldots$, 63];

- $\boldsymbol{i}_{7}$ is the index of standardized radial shaft seal for the output shaft, integer values in the range $[0, \ldots, 127]$;

The objective function. In this paper, the objective function is the mass of the entire single-row planetary gearbox (i.e the mass of his components-the gearings, the shafts, and the housing). The equation of the mass is presented in Eq. (1).
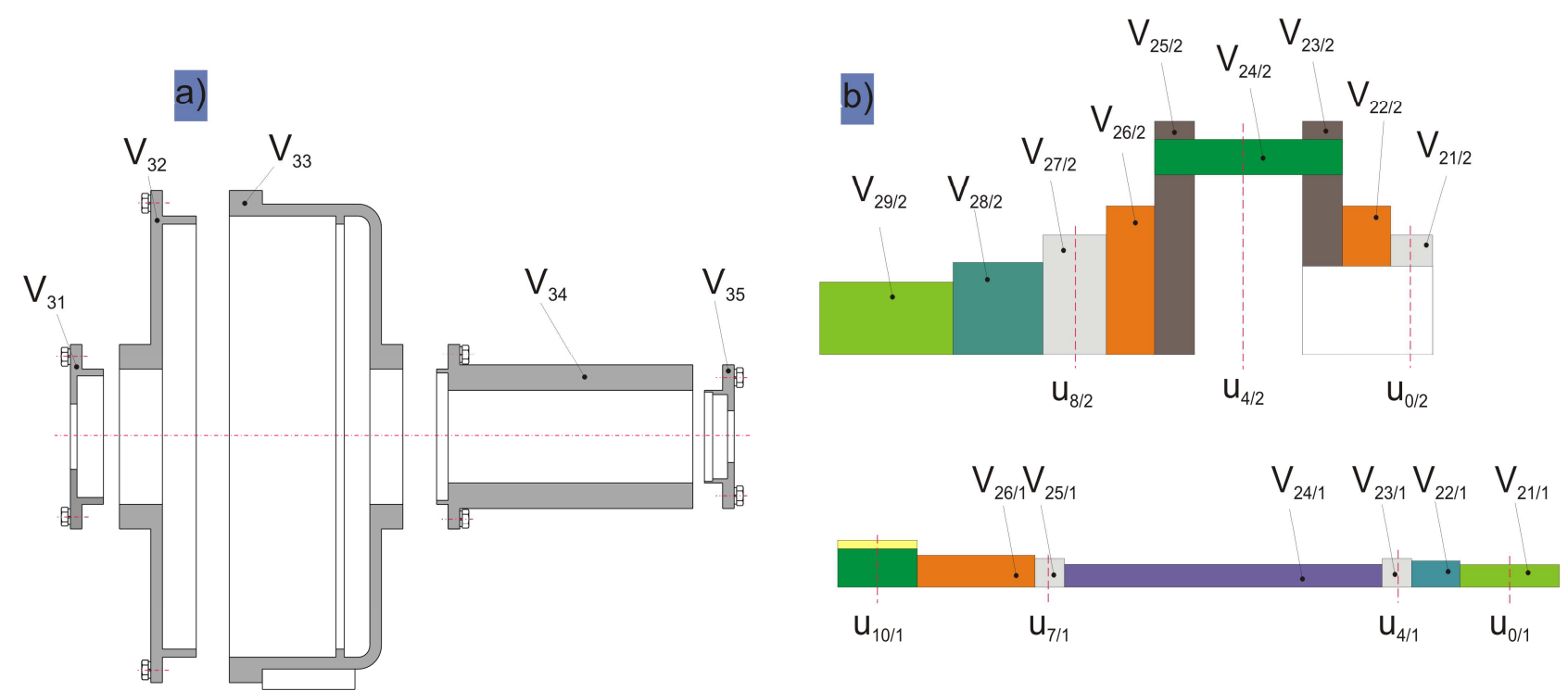

Fig. 2 The representation of the objective function (i.e. the volume) for the optimal design problem

$$
\text { Obj: } F(x)=m_{1}+m_{2 / 1}+m_{2 / 2}+m_{3}=\sum_{i=1}^{2} V_{1 i} \cdot \rho_{1}+\sum_{j=1}^{6} V_{2 j / 1} \cdot \rho_{1}+\sum_{k=1}^{9} V_{2 k / 2} \cdot \rho_{1}+\sum_{l=1}^{5} V_{3 l} \cdot \rho_{2} \text {. }
$$

where: $V_{1 i}$ - represents the volume of the gearings $\left(\mathrm{mm}^{3}\right) ; V_{2 j / 1}-$ is the volume of the first shaft $\left(\mathrm{mm}^{3}\right), V_{2 k / 2}$ - is the volume of the second shaft $\left(\mathrm{mm}^{3}\right), V_{3 l}$ - is the volume of the gearbox housing $\left(\mathrm{mm}^{3}\right) ; \rho_{1}-$ is the density of steel $\left(\rho_{1}=7.85 \cdot 10^{-6} \mathrm{~kg} / \mathrm{mm}^{3}\right) ; \rho_{2}-$ is the density of cast iron $\left(\rho_{2}=\right.$ $7.2 \cdot 10^{-6} \mathrm{~kg} / \mathrm{mm}^{3}$ ). These volumes are presented in Fig. 2 .

The constraints. There are a total of 59 constraints, which were structured into 4 major groups. As it could be observed these constraints are all of the inequality type, involving geometrical or structural considerations. The solutions of the optimization problem have to satisfy the following list of constraints which should be viewed with reference to the sketch illustrated in Fig. 1.

Constraints group 1. The adjacency, mounting and coaxiality conditions should be satisfied.

$$
\begin{aligned}
& g_{1}(x)=2 \cdot a_{w} \cdot \sin \left(\pi / n_{w}\right) \geq d_{a 2} . \\
& g_{2}(x)=\left(z_{1}+z_{2}\right) / n_{w}=\text { integer. } \\
& g_{2}(x)=\left|z_{1}+2 \cdot z_{2}-z_{3}\right| / n_{w} \leq 2 .
\end{aligned}
$$

where: $d_{a 2}-$ is the tip diameter of the planetary pinion; $z_{1,2,3}-$ are the numbers of teeth on planetary gears. 
Constraints group 2. Set of 24 constraints regarding the gearings (the gearing calculations are according to the relevant industrial standard document DIN 1987 [11]) of the single-row planetary gearbox.

$$
\begin{aligned}
& g_{4}(x)=\sigma_{H} \leq \sigma_{H P} . \\
& g_{5,6}(x)=\sigma_{F 1,2} \leq \sigma_{F P} . \\
& g_{7,8}(x)=\left(14-z_{1,2}\right) \leq 17 x_{1,2} . \\
& g_{9,10,11}(x)=c_{s a} m \leq s_{a 1,2,3} . \\
& g_{12,13}(x)=\varepsilon_{a i, e} \leq \varepsilon_{\alpha} . \\
& g_{14,15}(x)=\left|x_{2,3}-0.25\right| \leq 0.75 . \\
& g_{16}(x)=d_{b 3}^{2}+4 a_{w} \sin ^{2} \alpha_{w} \leq d_{a 3}^{2} . \\
& g_{17,18}(x)=z_{2} \varphi_{2 i, 3 e} \leq z_{3} \varphi_{3 i, 2 e} . \\
& g_{19}(x)=\rho_{A 1} \leq \rho_{N 1} . \\
& g_{20}(x)=\rho_{N 1} \leq \rho_{a 1} . \\
& g_{21}(x)=\rho_{E 2} \leq \rho_{N 2} . \\
& g_{22}(x)=\rho_{N 2} \leq \rho_{a 2} . \\
& g_{23}(x)=\rho_{A 2} \leq \rho_{N 2} . \\
& g_{24}(x)=\rho_{N 3} \leq \rho_{E 3} . \\
& g_{25}(x)=\rho_{a 3} \leq \rho_{N 3} . \\
& g_{26,27}(x)=\left\{\begin{array}{l}
-1\left(z_{1,2}, z_{2,3}\right)=1 \\
1\left(z_{1,2}, z_{2,3}\right) \neq 1
\end{array} .\right.
\end{aligned}
$$

where: $\boldsymbol{g}_{4}(\boldsymbol{x})$ is for Hertzian contact pressure on external toothing of the central wheel (1) and planetary pinions $(2)\left(\sigma_{H}-\right.$ the Hertz contact stress; $\sigma_{H P}-$ the allowable Hertz contact stress); $\boldsymbol{g}_{5,6}(\boldsymbol{x})$ are for bending stress on the teeth of the central wheel (1) and of the planetary pinions $(2)\left(\sigma_{F 1,2}-\right.$ bending stresses; $\sigma_{F P}-$ allowable bending stress), $\boldsymbol{g}_{7,8}(\boldsymbol{x})$ the teeth on central wheel (1) and on the planetary pinions (2) must not be undercut ( $x_{1,2}-$ tooth addendum coefficient); $\boldsymbol{g}_{9-11}(\boldsymbol{x})$ are for the top land of the teeth on gears of the single-row planetary gearbox which must not vanish $\left(c_{s a}=0.25\right.$; $m$ - module; $s_{a 1,2,3}$ - the outside cylinder circular tooth thickness); $\boldsymbol{g}_{\mathbf{1 2}, \mathbf{1 3}}(\boldsymbol{x})$ are for the contact ratio of the external toothing of the wheels (1) and (2), and of the internal toothing of the wheels (2) and (3) which must be greater than a specified value $\left(\varepsilon_{\alpha i, e}\right.$ - radial contact ratio for internal and external toothing; $\left.\varepsilon_{\alpha}=1,2\right) ; \boldsymbol{g}_{\mathbf{1 4 , 1 5}}(\boldsymbol{x})$ are for the addendum coefficients of the planetary pinions (2) and of the stationary central wheel (3), which should be in the range $[-0.5,1] ; \boldsymbol{g}_{16-18}(x)$ are to avoid the interference of the internal toothing of wheels (2) and (3) $\left(d_{b 3}, d_{a 3}\right.$ - base and tip diameter of stationary central wheel); $\boldsymbol{g}_{\mathbf{1 9 - 2 5}}(\boldsymbol{x})$ are about the measurability conditions for all the wheels of the single-row planetary gearbox $\left(\rho_{a 1}, \rho_{a 2}, \rho_{a 3}\right.$ curvature profile radii; $\rho_{A 1}, \rho_{A 2}$ curvature profile radii in the first point of contact; $\rho_{E 2}, \rho_{E 3}$ curvature profile radii in the last point of contact; $\rho_{N 1}, \rho_{N 2}, \rho_{N 3}$ curvature profile radii in the measurement points of span in radial direction); $\boldsymbol{g}_{\mathbf{2 6 , 2 7}}(\boldsymbol{x})$ are about the matching numbers of teeth on the gears of external and internal gearings which should be relative primes.

Constraints group 3. Set of 31 constraints regarding the shafts of the single-row planetary gearbox.

$$
g_{28,29}(x)=1.15 \cdot d_{e s 1,2} \leq d_{r s 1,2} .
$$




$$
\begin{aligned}
& g_{30,31}(x)=d_{r s 1,2} \leq d_{r b b 1,2} . \\
& g_{32,33}(x)=\left(D_{r s 1,2}+x_{3}\right) \leq D_{a \max r r b 1,2} . \\
& g_{34}(x)=d_{a \min r b b 1} \leq d_{f 1} . \\
& g_{35}(x)=\left(3 \cdot x_{5}+B_{r b b 2}+u_{1 / 8}\right) \leq u_{1 / 9} . \\
& g_{36}(x)=\left(d_{a 1}+x_{12}\right) \leq d_{r b b 2 .} . \\
& g_{37,38}(x)=\sigma_{m v M 1,2} \leq \sigma_{a b I I I 1,2} . \\
& g_{39,40}(x)=\min L S F_{1,2}(p) \geq c_{a} . \\
& g_{41,42}(x)=\theta_{1,2} \leq \theta_{a} . \\
& g_{43}(x)=\delta\left(u_{1 / 0}\right) \leq \delta_{a} . \\
& g_{44}(x)=\delta\left(u_{1 / 10}\right) \leq \delta_{a} . \\
& g_{45}(x)=\delta\left(u_{2 / 4}\right) \leq \delta_{a} . \\
& g_{46}(x)=\varphi\left(u_{1 / 4}\right) \leq \varphi_{a} . \\
& g_{47}(x)=\varphi\left(u_{1 / 7}\right) \leq \varphi_{a} . \\
& g_{48}(x)=\varphi\left(u_{2 / 0}\right) \leq \varphi_{a} . \\
& g_{49}(x)=\varphi\left(u_{2 / 8}\right) \leq \varphi_{a} . \\
& g_{50,51}(x)=L_{h} \geq L_{s p e c i f} . \\
& g_{52,53}(x)=\sigma_{c 1,2} \geq \sigma_{a c} . \\
& g_{54,55}(x)=\tau_{s 1,2} \geq \tau_{a s} . \\
& g_{56}(x)=\sigma_{b b o l t} \leq \sigma_{a b} . \\
& g_{57}(x)=\tau_{s b o l t} \leq \tau_{a s} . \\
& g_{58}(x)=p_{c b o l t} \leq p_{a c} .
\end{aligned}
$$

where: $\boldsymbol{g}_{\mathbf{2 8 , 2 9}}(\boldsymbol{x})$ the input/output shaft ends must have a sufficient diameter step to allow the mounting of a belt wheel ( $d_{e s 1,2}-$ input/output shaft ends diameters; $d_{r s 1,2}$ - input/output radials seals inner diameters); $\boldsymbol{g}_{\mathbf{3 0 , 3 1}}(\boldsymbol{x})$ the inside diameter of the radial ball bearings on the shafts must be less than the mounting diameter of the seal $\left(d_{r b b 1,2}\right.$ - the inside diameter of the radial ball bearings on the input/output shafts); $\boldsymbol{g}_{\mathbf{3 2 , 3 3}}(\boldsymbol{x})$ constraints relating to the space required by the outside ring of the radial ball bearings on the shafts $\left(D_{r s 1,2}\right.$ outside diameter of the radial seals; $x_{3}=3 ; D_{\text {amaxrbb1,2 }}-$ geometrical dimensions regarding the radial ball bearings [12]); $\boldsymbol{g}_{\mathbf{3 4 - 3 6}}(\boldsymbol{x})$ a manufacturability constraint of the central wheel (1) $\left(d_{\text {aminrbb1,2 }}\right.$ - geometrical dimensions regarding the radial ball bearings; $d_{f 1}$ - central wheel root diameter; $\mathrm{x}_{5}=5 ; B_{r b b 2}$ - the width of the radial ball bearing of the output shaft; $\left.x_{12}=10\right) ; \boldsymbol{g}_{37,38}(\boldsymbol{x})$ the maximum von Misses equivalent stresses experienced by the shafts must not exceed a certain value $\left(\sigma_{a b I I I 1}=90 \mathrm{MPa}\right.$ for $42 \mathrm{MoCr} 4$ and $\sigma_{a b I I I 2}=65 \mathrm{MPa}$ for C45); $g_{39,40}(x)$ - constraints about the fatigue life safety factors on the input/output shafts $\left(\mathrm{c}_{\mathrm{a}}=1.5\right)$; $\boldsymbol{g}_{\mathbf{4 1 , 4 2}}(\boldsymbol{x})$ - the torsional strains in the both shafts must be below a threshold value; $\boldsymbol{g}_{43-45}(\boldsymbol{x})$ - the bending stresses on the shafts in sections $u_{1 / 0}, u_{1 / 10}$ and $u_{2 / 4}$ must be below certain threshold values to enable the correct functioning of the gearings and the bearings $\left(\delta_{\mathrm{a}}=0.025 \cdot \mathrm{m}\right) ; \boldsymbol{g}_{46-49}(\boldsymbol{x})-$ the deflection at the supporting point in sections $u_{1 / 4}\left(u_{2 / 0}\right)$ and $u_{1 / 7}\left(u_{2 / 8}\right)$ for input/output shaft must not exceed certain allowable value $\left(\varphi_{\mathrm{a}}=0.008 \mathrm{rad}\right) ; \boldsymbol{g}_{\mathbf{5 0 , 5 1}}(\boldsymbol{x})$ - the service life of the radial ball bearings must exceed a specified value; $\boldsymbol{g}_{52-55}(\boldsymbol{x})$ the shearing and crushing stresses must not exceed a specified value on the keys and keyways $\left(\sigma_{a c}=50 \mathrm{MPa}, \tau_{a s}=80 \mathrm{MPa}\right.$ for E360); $\boldsymbol{g}_{56-58}(\boldsymbol{x})$ bending, shearing and crushing stresses for the bolt on which are mounted the planetary pinions must not exceed a specific value $\left(\sigma_{a b}=65 \mathrm{MPa}, \tau_{a s}=72 \mathrm{MPa}, p_{a c}=10\right.$ for C45). 
Constraints group 4. The operating temperature of the single-row gearbox must not exceed a specified value.

$$
g_{59}(x)=t_{O} \leq t_{a}
$$

where $t_{a}=60{ }^{0} \mathrm{C}$

\section{An effective example of a 2 K-h single-row planetary gearbox optimal design}

A $2.9 \mathrm{~kW}$ single-row planetary gearbox (Fig.2) is to be designed for minimum mass and a service life of $8000 \mathrm{~h}$, given an input speed of $925 \mathrm{rpm}$ and a transmission ratio of 7.6. The singlerow planetary gearbox gears should be based on an ISO 53 basic rack profile and should be made of quenched and tempered alloy steel 42CrMo4. Running the GA, led to a single-row planetary gearbox weighing $32.5649 \mathrm{~kg}$. The values of all considered design variables, after optimization, are presented in Table 1.

Table 1 The values of the genes obtained after optimization

\begin{tabular}{|c|c|c|c|c|c|c|c|c|c|c|c|c|c|}
\hline$z_{1}$ & $n_{w}$ & $a_{w}$ & $x_{1}$ & $\psi_{a}$ & $\Delta u$ & $r d$ & $i_{1}$ & $i_{2}$ & $i_{3}$ & $i_{4}$ & $i_{5}$ & $i_{6}$ & $i_{7}$ \\
\hline 22 & 2 & 71 & -0.1693 & 0.6205 & -0.0306 & 0 & 29 & 23 & 57 & 39 & 28 & 101 & 72 \\
\hline
\end{tabular}

In Tables 2 and 3, the main characteristics of the gearings and of the shafts (traditional design and optimal solutions) are shown side-by-side.

Table 2 The main geometrical dimensions of the single-row planetary gearbox

\begin{tabular}{|c|c|c|}
\hline Symbol & $\begin{array}{c}\text { Traditional } \\
\text { design solution }\end{array}$ & $\begin{array}{c}\text { Optimal design } \\
\text { solution }\end{array}$ \\
\hline$z_{1}$ & 21 & 22 \\
\hline$z_{2}$ & 58 & 59 \\
\hline$z_{3}$ & 137 & 140 \\
\hline$m(\mathrm{~mm})$ & 2.25 & 1.75 \\
\hline$a_{w}(\mathrm{~mm})$ & 90 & 71 \\
\hline$b_{1}(\mathrm{~mm})$ & 37 & 51 \\
\hline$b_{2}(\mathrm{~mm})$ & 34 & 46 \\
\hline$b_{3}(\mathrm{~mm})$ & 32 & 44 \\
\hline$d_{b 1}(\mathrm{~mm})$ & 44.4004 & 36.1781 \\
\hline$d_{b 2}(\mathrm{~mm})$ & 122.6298 & 97.0232 \\
\hline$d_{b 3}(\mathrm{~mm})$ & 289.6602 & 230.2246 \\
\hline$d_{f 1}(\mathrm{~mm})$ & 43.875 & 33.5324 \\
\hline$d_{f 2}(\mathrm{~mm})$ & 124.978 & 99.7192 \\
\hline$d_{f 3}(\mathrm{~mm})$ & 316.331 & 250.4708 \\
\hline$d_{w 1}(\mathrm{~mm})$ & 47.8481 & 38.5679 \\
\hline$d_{w 2}(\mathrm{~mm})$ & 132.1518 & 103.432 \\
\hline$d_{w 3}(\mathrm{~mm})$ & 312.1518 & 245.432 \\
\hline$d_{a 1}(\mathrm{~mm})$ & 53.8969 & 41.4057 \\
\hline$d_{a 2}(\mathrm{~mm})$ & 135 & 107.5925 \\
\hline$d_{a 3}(\mathrm{~mm})$ & 306.103 & 242.5942 \\
\hline$\sigma_{H}(\mathrm{MPa})$ & 541.0663 & 593.0539 \\
\hline$\sigma_{H P}(\mathrm{MPa})$ & 603.161 & 592.053 \\
\hline$\sigma_{F 1}(\mathrm{MPa})$ & 89.9949 & 126.1423 \\
\hline$\sigma_{F P 1}(\mathrm{MPa})$ & 475.7503 & 463.2207 \\
\hline$\sigma_{F 2}(\mathrm{MPa})$ & 99.2319 & 328.6006 \\
\hline$\sigma_{F P 2}(\mathrm{MPa})$ & 473.0028 & 476.1955 \\
\hline
\end{tabular}


Table 3 The geometrical dimensions of the single-row planetary gearbox shafts

\begin{tabular}{|c|c|c|}
\hline Symbol & $\begin{array}{c}\text { Traditional } \\
\text { design solution }\end{array}$ & $\begin{array}{c}\text { Optimal design } \\
\text { solution }\end{array}$ \\
\hline$d_{e s 1}(\mathrm{~mm})$ & 21 & 25 \\
\hline$d_{e s 2}(\mathrm{~mm})$ & 58 & 32 \\
\hline$d_{r s 1}(\mathrm{~mm})$ & 22 & 30 \\
\hline$d_{r s 2}(\mathrm{~mm})$ & 44 & 38 \\
\hline$D_{r s 1}(\mathrm{~mm})$ & 32 & 50 \\
\hline$D_{r s 2}(\mathrm{~mm})$ & 60 & 72 \\
\hline$B_{r s 1}(\mathrm{~mm})$ & 7 & 8 \\
\hline$B_{r s 2}(\mathrm{~mm})$ & 10 & 10 \\
\hline$d_{r b b 1}(\mathrm{~mm})$ & 25 & 30 \\
\hline$d_{r b b 2}(\mathrm{~mm})$ & 70 & 55 \\
\hline$D_{r b b 1}(\mathrm{~mm})$ & 47 & 55 \\
\hline$D_{r b b 2}(\mathrm{~mm})$ & 90 & 80 \\
\hline$B_{r b b 1}(\mathrm{~mm})$ & 12 & 9 \\
\hline$B_{r b b 2}(\mathrm{~mm})$ & 10 & 13 \\
\hline$\sigma_{m v M 1}(\mathrm{MPa})$ & 44.7486 & 24.3001 \\
\hline$\sigma_{m v M 2}(\mathrm{MPa})$ & 50.2824 & 50.6785 \\
\hline$\delta\left(u_{1 / 0}\right)(\mathrm{mm})$ & 0.0463 & 0.0355 \\
\hline$\delta\left(u_{1 / 10}\right)(\mathrm{mm})$ & 0.0514 & 0.0367 \\
\hline$\delta\left(u_{2 / 4}\right)(\mathrm{mm})$ & 0.0018 & 0.0038 \\
\hline$\varphi\left(u_{1 / 4}\right)(\mathrm{rad})$ & 0.00074 & 0.00041 \\
\hline$\varphi\left(u_{1 / 7}\right)(\mathrm{rad})$ & 0.00076 & 0.00043 \\
\hline$\varphi\left(u_{2 / 0}\right)(\mathrm{rad})$ & 0.000062 & 0.0001 \\
\hline$\varphi\left(u_{2 / 8}\right)(\mathrm{rad})$ & 0.000061 & 0.00011 \\
\hline$L S F_{1}$ & 3.7406 & 5.6695 \\
\hline$L S F_{2}$ & 6.5257 & 4.096 \\
\hline$O_{b j j}(\mathrm{~kg})$ & $\mathbf{3 8 . 3 8 5 7}$ & $\mathbf{3 2 . 5 6 4 9}$ \\
\hline
\end{tabular}

From Table 2 and Table 3, two important conclusions could be drawn: 1) the module $(m)$ and the centre distance $\left(a_{w}\right)$ (two of the standardized design variables) have diminished theirs values with $21.65 \%$; 2) the optimal design solution offers a reduction of mass $15.16 \%$ as compared to traditional design solution. In the case of large series production the advantages of the proposed method are obviously-the manufacturing costs are significantly diminished. For example at $\approx 7$ gearboxes produced, 1 is for free considering the material.

\section{Conclusions}

In this paper a GA methaeuristics is proposed for solving the complex structural design problem of a $2 \mathrm{~K}$-h single-row planetary gearbox. The objective of this study was the minimization of the whole gearbox mass. The optimal design solution obtained after optimization was compared to the traditional design (i.e. a trial and cut error procedure). The objective function was subjected to a set of 59 constraints (structured in 4 major groups: 1)-the adjacency, the mounting and the coaxially conditions; 2)-24 constraints for the gears; 3)-31 regarding the shafts; 4)-1 for the operating temperature). The design variables considered in the optimization were of mixed nature i.e., continuous, integer, and discrete in total of 14. The results of the optimised planetary gearbox suggest a reduction of the mass with $15.16 \%$ as compared with the situation when the traditional design was used. 


\section{Acknowledgment}

This paper was supported by the project "Development and support of multidisciplinary postdoctoral programmes in major technical areas of national strategy of Research - Development Innovation" 4D-POSTDOC, contract no. POSDRU/89/1.5/S/52603, project co-funded by the European Social Fund through Sectoral Operational Programme Human Resources Development 2007-2013.

\section{References}

[1] G. Madhusudan, C.R. Vijayasimha, Approach to spur gear design, Computer-Aided Design, 19 (1987) 555-559.

[2] B. Aberšek, J. Flasker, J. Balic, Expert system for designing and manufacturing of a gear box, Expert Systems with Applications, 11 (1996) 397-405.

[3] C. Gologlu, M. Zeyveli, A genetic approach to automate preliminary design of gear drives, Computers \& Industrial Engineering, 57 (2009) 1043-1051.

[4] O. Buiga, C.O. Popa, Optimal mass design of a single-stage helical gear unit with Genetic Algorithms, Proceedings of Romanian Academy, Series A, 13 (2012) 243-250.

[5] L. Tudose, O. Buiga, C. Stefanache, A. Sobester, Automated optimal design of a two-stage helical gear reducer, Structural and Multidisciplinary Optimization, 42 (2010) 429-435.

[6] D.R. Salgado, F.J. Alonso, F.J. Optimal mechanical spindle speeder gearbox design for highspeed machining, International Journal of Advanced Manufacturing Technology, 40 (2009) 637647.

[7] P. Bentley, An introduction to evolutionary design by computers, Evolutionary Design by Computers, Morgan Kaufmann, 1999.

[8] J.H Holland, Adaptation in Natural and Artificial Systems, Ann Arbor: The University of Michigan Press, 1975.

[9] G. Renner, A. Ekárt, Genetic algorithms in computer aided design, Computer-Aided Design, 35 (2003) 709-726.

[10] K.H. Grote, E.K. Antonsson, Springer Handbook of Mechanical Engineering, Springer, 2009.

[11]DIN 3990, Teil 3 Tragfähigkeitsberechnung von Stirnrädern, Deutsches Institut Für Normung $\mathrm{EV}, 1987$.

[12] http://www.skf.com 